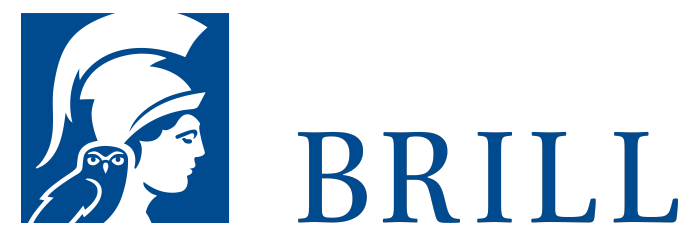

\title{
Der deskriptive Kern der Verantwortung
}

Eine metaethische Untersuchung angesichts

neurokognitionswissenschaftlicher Erkenntnisse

Author: Sebastian Wolf

In der Metaethik gibt es eine Position, die behauptet, dass unsere moralische Praxis, wie wir sie derzeit aus $\tilde{A}^{1 / 4} \mathrm{~b}$ ben, aus empirischen GrÃ $1 / 4$ nden nicht gerechtfertigt werden kann. Der Hauptfehler dieser revisionistischen Argumentation liegt in ihrer Versteifung auf die Unterscheidung von bewussten und unbewussten Handlungen. Diese Studie argumentiert, dass fÃ $1 / 4$ r verantwortliches Handeln ein deskriptiver Kern von Verantwortung gegeben sein muss, der von dieser Unterscheidung unabhÃongig ist. Er besteht erstens aus einer Form von Autonomie, die verstanden wird als Handlungen, die das Kernselbst der Person ausdrÃ $1 / 4$ cken. Und er besteht zweitens aus einer Form von rationaler Kontrolle, die verstanden wird als eine, die nicht allein relativ zu den eigenen PrÃ aferenzen der Person ist, sondern auch relativ zu objektiv geltenden GrÃ $1 / 4$ nden - sie wird verstanden als orthonome Kontrolle. Die entscheidende Dichotomie fã $1 / 4 \mathrm{r}$ verantwortliches Handeln ist demnach vielmehr die zwischen aktiv und passiv, zwischen dynamisch und statisch. Weil Personen im Normalfall ihr Verhalten und ihren Charakter aktiv, flexibel und dynamisch ihren UmstÃanden anpassen $\mathrm{kÃ} \llbracket$ nnen, sind sie daher angemessene Verantwortungssubjekte.

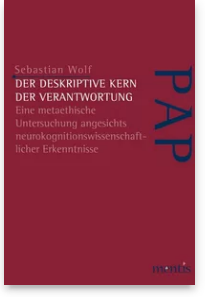

Pages: 254

Seiten

Language:

German

Subjects:

General, Philosophy

Publisher: Brill | mentis

Series:

Perspektiven der Analytischen

Philosophie

E-Book (PDF)

Released online: 2o Apr 2012

ISBN: 978-395743-979-6

List price USD Â $\$$ \$6.0o

Paperback Publication date: 2o Apr 2012 ISBN: 978-389785-224-2 List price USDD Â \$60.00 
For more information see brill.com

Order information: Order online at brill.com +44330 333 0049 | customerservices@brill.com Submission information: brill.com/authors

Titles published by Brill | Fink, Brill | mentis or Brill | Schöningh: +49(o)715413279216| brill@brocom.de 